\title{
Effect of SARS-CoV-2 spike mutations on its activation by TMPRSS2 and TMPRSS13
}

Annelies Stevaert ${ }^{1}$, Ria Van Berwaer ${ }^{1}$, Valerie Raeymaekers ${ }^{1}$, Manon Laporte ${ }^{2,3}$ and Lieve Naesens ${ }^{1^{*}}$

${ }^{1}$ KU Leuven, Dept. Microbiology, Immunology and Transplantation, Rega Institute, Leuven, Belgium

2 Department of Microbiology, Icahn School of Medicine at Mount Sinai, New York, NY 10029, USA

${ }^{3}$ Global Health and Emerging Pathogens Institute, Icahn School of Medicine at Mount Sinai, New York, NY 10029, USA

*Corresponding author: lieve.naesens@kuleuven.be

Running title: SARS-CoV-2 spike activation by TMPRSS2 and TMPRSS13 


\section{ABSTRACT}

The continuous emergence of new SARS-CoV-2 variants urges better understanding of the functional motifs in the spike (S) protein and their tolerance towards mutations. We here focus on the $S 2$ ' motif which, during virus entry, requires cleavage by a cell surface protease to release the fusion peptide. Though belonging to an immunogenic region, the SARS-CoV-2 S2' motif (811-KPSKR-815) has shown hardly any variation, with its three basic $(K / R)$ residues being $>99.99 \%$ conserved thus far. By creating a series of mutant S-pseudotyped viruses, we show that $\mathrm{K}_{814}$, which precedes the scissile $\mathrm{R}_{815}$ residue, is dispensable for SARS-CoV-2 spike activation by TMPRSS2 but not TMPRSS13. The latter protease lost its activity towards SARS-CoV-2 S when the S2' motif was swapped with that of the low pathogenic 229E coronavirus (685RVAGR-689) and also the reverse effect was seen. This swap had no impact on TMPRSS2 activation. Also in the MERS-CoV spike, introducing a dibasic scissile motif was fully accepted by TMPRSS13 but less so by TMPRSS2. Our findings are the first to demonstrate which S2' residues are important for SARS-CoV-2 spike activation by these two airway proteases, with TMPRSS13 exhibiting higher preference for $\mathrm{K} / \mathrm{R}$ rich motifs than TMPRSS2. This preemptive insight can help to estimate the impact of S2' motif changes as they may appear in new SARS-CoV-2 variants.

\section{IMPORTANCE}

Since the start of the COVID-19 pandemic, SARS-CoV-2 is undergoing worldwide selection with frequent appearance of new variants. The surveillance would benefit from proactive characterization of the functional motifs in the spike protein, the most variable viral factor. This is linked to immune evasion but also influences spike functioning in a direct manner. Remarkably, though located in a strong immunogenic region, the S2' cleavage motif has, thus far, remained highly conserved. This suggests that its amino acid sequence is critical for spike activation by airway proteases. To investigate this, we assessed which S2' site mutations affect processing by TMPRSS2 and TMPRSS13, two main activators of the SARS-CoV-2 spike. Being the first in its kind, our study will help to assess the biological impact of S2' site variations as soon as they are detected during variant surveillance.

\section{KEYWORDS}

SARS-CoV-2, human coronavirus 229E, spike protein, mutation, protease, cleavage, TMPRSS2, TMPRSS13 
Since the start of the COVID-19 pandemic, SARS-CoV-2 is undergoing worldwide selection with frequent appearance of new variants. The variability in the viral spike (S) antigen is linked to immune evasion but also affects the functioning of $S$ in virus replication and transmission. For instance, substitution D614G, which arose in March 2020 to soon become dominant, increases S protein stability $(1,2)$ and virus transmission $(3,4)$. Mutation P681R, present in the delta and kappa variants and located adjacent to the S1/S2 furin recognition motif (RRAR), enhances spike fusogenicity and virus pathogenicity in hamsters (5). The reverse is seen for the omicron variant $(6,7)$. Knowing which residues in the functional spike motifs are essential or not, can help to assess the impact of new variations as they emerge. In this report, we focus on the S2' motif.

Cleavage of the SARS-CoV-2 S1/S2 site facilitates cleavage at the S2' site, a process essential to release the fusion peptide. Two efficient $S 2$ ' activators are TMPRSS2 (8) and TMPRSS13 $(2,9,10)$ which are both expressed in respiratory tissue (11). In a SARS-CoV-2 mouse model, TMPRSS2 knockout resulted in less lung pathology and lower virus titers, although the virus was still able to replicate in the lungs (12). In human airway-derived Calu-3 cells, knockdown of TMPRSS2 reduced virus replication dramatically $(2,13)$, yet also TMPRSS13 knockdown had significant effect (2). The activating role of TMPRSS2, but not that of TMPRSS13, was confirmed in human airway organoids (14). Hence, the relative contribution of these two proteases in SARS-CoV-2 infection remains unclear.

Low variability and K/R abundance in the S2' site. Within the SARS-CoV-2 S2' motif (811-KPSKR-815), the scissile $R_{815}$ residue is flanked by a second basic $\left(K_{814}\right)$ residue. The motif lies in a strong epitope $(15,16)$ for which the antibody titers seem correlated with COVID-19 disease severity (17). Despite this high immunogenicity, the S2' motif exhibits strikingly low variability. When we analyzed the $\sim 6.7$ million spike sequences in the GISAID database (Fig. 1A), all three basic residues in the S2' motif ( $=\mathrm{K}_{811}, \mathrm{~K}_{814}$ and $\mathrm{R}_{815}$ ) proved highly dominant, being present in $>99.99 \%$ of the sequences. This is less surprising for $R_{815}$ (in only a few cases substituted by $K$ ), the presumed scissile residue (18). $P_{812}$ and $S_{813}$ are somewhat more tolerant towards variation, consistent with the presence of $T_{813}$ in the SARS-CoV spike (19).

Mutations at the S2' motif do not affect spike expression or S1/S2 cleavage. The high conservation of the SARS-CoV-2 KxxKR motif suggests that its sequence is essential for spike activation. Strikingly, a dibasic scissile motif is missing in all five endemic less pathogenic human coronaviruses (HCoVs) including HCoV-229E (19), while MERS-CoV bears an $x \operatorname{Rx} x \mathrm{R}$ motif (Fig. 1B). Hence, we designed a series of 
S2'-mutated S proteins (abbreviated SARS-2-S, MERS-S and 229E-S; Fig. 1B) in which we swapped the motifs from SARS-2-S and 229E-S or introduced or removed a Lys (K) at P2 or an Arg (R) at P4 (since MERS-S contains a basic residue at P4 but not P5). S-bearing MLV-pseudoparticles were produced in HEK293T cells, pelleted down and analyzed for spike levels and cleavage by western blot (Fig. 2A). All S2'mutant pseudovirions contained similar $S$ protein levels as the respective WT (Fig. 2B). For the SARS-2-S- and MERS-S-pseudoparticles, efficient spike cleavage was seen for all S2'mutants. Even a change of 4 out of 5 residues (= SARS-2-S-Mut3) had no effect on spike expression or S1/S2 cleavage. For 229E-S, the WT and mutants contained similar levels of several cleavage products.

SARS-2-S containing the S2' motif of 229E-S loses TMPRSS13 cleavability. We next conducted an entry assay to measure S2' activation by TMPRSS2 and TMPRSS13. The S-pseudoviruses were transduced into HEK293T cells which were transfected one day earlier with TMPRSS2-, TMPRSS13- or empty plasmid, plus the cognate virus receptor (Fig. 2A). Transduction was performed in the presence of E64d to shut off the endosomal route in which $S$ is activated by cathepsin $B / L$ instead of cell surface proteases (20).

As expected $(2,8,21)$, TMPRSS2 proved an efficient activator of the three CoV spike proteins, giving an increase in S-driven pseudovirus entry (compared to cells transfected with empty plasmid) of 378, 244 and 23 for the WT forms of SARS-2-S, MERS-S and 229E-S, respectively (Fig. 2C). The lower value for $229 \mathrm{E}-\mathrm{S}$ is explained by lower levels of functional $S$ in these pseudovirions, due to unspecific cleavage (see above). 229E-S was not activated by TMPRSS13, in sharp contrast with efficient usage of this protease by SARS-2-S and MERS-S. Regarding the S2' mutants, neither was severely affected for TMPRSS2 usage. The only exception was SARS-2S-Mut2 showing that TMPRSS2-driven entry was 92-fold reduced when the P at P4 was substituted by $R$. Removing the basic charge at P2 (=K to A; Mut1) or swapping the motif of SARS-2-S for that of 229E-S (Mut3) gave only 2-fold reduction in activation by TMPRSS2. In stark contrast, these mutations had significantly $(\mathrm{P}<$ $0.001)$ negative impact on TMPRSS13-driven entry, the fold reduction versus SARS2-S WT being 27- (Mut1), 40- (Mut2) and as high as 155-fold for Mut3. Hence, introducing the 229E-S2' motif into SARS-2-S abolished the capacity of TMPRSS13 to activate this spike. Inversely, 229E-S gained the ability to use TMPRSS13 for entry activation, when bearing the SARS-2-S2' motif (Mut1; 7.1-fold) or its K at P2 (Mut2; 4.7-fold). 
For MERS-S, activation by TMPRSS2 was significantly yet only 3.4-fold reduced when the motif contained a third basic residue (Mut1). Substituting the R at P4 (Mut2) had no (TMPRSS2) or only minor (TMPRSS13) influence.

During the above experiments, equal amounts of TMPRSS2- and TMPRSS13plasmid DNA were applied for HEK293T cell transfection. Dot blot analysis demonstrated that this generated comparable protein levels for both proteases (Fig. 2D). This excluded the possibility that low expression of TMPRSS13 might be the reason for poor activation of some pseudoviruses.

Discussion. This study anticipates on the relevance of $\mathrm{S}^{\prime}$ site changes as they may appear in new SARS-CoV-2 variants. Since the S2' motif lies in a strong epitope (15, 17 ), the virus might acquire mutations in this region to evade immunity. The fact that such variations are, thus far, rarely detected could mean that the sequence of this $\mathrm{K} / \mathrm{R}$ rich motif is crucial for SARS-2-S activation by cell surface proteases. Our study is the first to address this topic. Clearly, residue $\mathrm{K}_{814}$ is important for TMPRSS13 but not TMPRSS2. This basic P2 residue differentiates SARS-2-S from 229E-S (and the spikes of all other low pathogenic HCoVs), which otherwise share a basic P5 residue. Making the motif even more basic by addition of an $\mathrm{R}$ at P4, causes a more dramatic reduction for TMPRSS2 than TMPRSS13. This aligns with data that basic residues at P2-P3-P4 are not favored by TMPRSS2 (22). Reciprocally, the preference of TMPRSS13 for a basic motif concurs with its activity on multibasic hemagglutinins of highly pathogenic avian influenza viruses (23). Combined with the presence of TMPRSS13 in human lung tissue (24), this raises the hypothesis that loss of TMPRSS13 cleavability, e.g. by mutation of $\mathrm{K}_{814}$, might reduce replication of SARSCoV-2 in the lungs. Though limited to a few mutations, our findings will help to

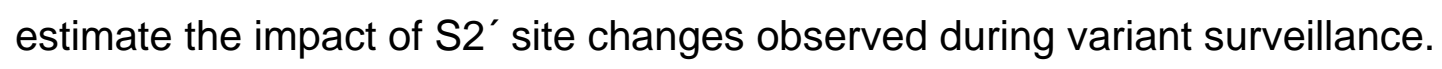

Experimental procedures. In this study, the WT spike sequences correspond to the published sequences with accession numbers: YP_009724390.1 (SARS-2-S; early pandemic D614 variant); YP_009047204.1 (MERS-S) and NP_073551.1 (229E-S). A detailed description of the methods under (i) to (iii) can be found elsewhere (2). (i) Pseudovirus production. Briefly, the plasmids encoding the WT spikes (with Cterminal V5-tag) were first submitted to site-directed mutagenesis. To produce Spseudotyped murine leukemia virus (MLV) particles, the S-plasmids were combined with the MLV gag-pol and firefly luciferase reporter plasmids and co-transfected into HEK293T cells. The pseudovirus-containing supernatants were collected after three days incubation at $33^{\circ} \mathrm{C}$ (SARS-2-S and $229 \mathrm{E}-\mathrm{S}$ ) or $37^{\circ} \mathrm{C}$ (MERS-S). (ii) Effect of 
TMPRSS2 and TMPRSS13 on pseudovirus entry. HEK293T cells were transfected with TMPRSS2-, TMPRSS13- or empty plasmid (11) combined with a plasmid encoding the suitable coronavirus receptor, i.e. angiotensin-converting enzyme 2 (ACE2; for SARS-2-S); dipeptidyl peptidase-4 (DPP4; for MERS-S) or aminopeptidase N (APN; for 229E-S). One day later, the cells were pre-incubated for $2 \mathrm{~h}$ with cathepsin inhibitor E64d, after which pseudovirus was added and allowed to enter for $2 \mathrm{~h}$. After replacing the medium, the cells were incubated for three days at $33^{\circ} \mathrm{C}$, to then measure the luciferase signal in a plate luminometer. (iii) Western blot analysis of spike expression and cleavage. After pseudovirus production [see (i)], the particles were pelleted from the supernatants by centrifugation on a sucrose cushion, after which they were mixed with RIPA buffer and submitted to denaturating PAGE. After blotting, the membranes were stained with anti-V5 and anti-MLV gag p30 antibodies combined with HRP-linked secondary antibody. (iv) Dot blot detection of TMPRSS2 and TMPRSS13. Two days after transfection with protease expression plasmid, extracts of the HEK293T cells were prepared in RIPA buffer, then spotted on nitrocellulose membranes in undiluted, or 1/2 and 1/4 diluted form. The membranes were stained with anti-flag antibody recognizing the N-terminal flag tag in the expressed TMPRSS2 and TMPSS13. All details can be found in a previous report (11). (v) Variation analysis. 6,679,700 spike sequences were downloaded from the GISAID database (25) on 04/01/2022 and variation around the S2' site was analyzed. 


\section{FUNDING}

This work is supported by funding from the European Union's Innovative Medicines Initiative (IMI) under Grant Agreement 101005077 [Corona Accelerated R\&D in Europe (CARE) project] and Fundació La Marató de TV3, Spain (Projects No. 201832-30 and No. 202135-30). M.L. holds a postdoctoral fellowship from the Belgian American Education Foundation (BAEF).

\section{ACKNOWLEDGMENTS}

The authors thank S. Pöhlmann and M. Hoffmann for the kind gift of plasmid materials.

\section{DISCLOSURE STATEMENT}

There are no relevant financial or non-financial competing interests to report. 


\section{REFERENCES}

1. Zhang L, Jackson CB, Mou H, Ojha A, Peng H, Quinlan BD, Rangarajan ES, Pan A, Vanderheiden A, Suthar MS, Li W, Izard T, Rader C, Farzan M, Choe H. 2020. SARS-CoV-2 spike-protein D614G mutation increases virion spike density and infectivity. Nat Commun 11:6013.

2. Laporte M, Raeymaekers V, Van Berwaer R, Vandeput J, Marchand-Casas I, Thibaut HJ, Van Looveren D, Martens K, Hoffmann M, Maes P, Pöhlmann S, Naesens L, Stevaert A. 2021. The SARS-CoV-2 and other human coronavirus spike proteins are fine-tuned towards temperature and proteases of the human airways. PLoS Pathog 17:e1009500.

3. Hou YJ, Chiba S, Halfmann P, Ehre C, Kuroda M, Dinnon KH, 3rd, Leist SR, Schafer A, Nakajima N, Takahashi K, Lee RE, Mascenik TM, Graham R, Edwards CE, Tse LV, Okuda K, Markmann AJ, Bartelt L, de Silva A, Margolis DM, Boucher RC, Randell SH, Suzuki T, Gralinski LE, Kawaoka Y, Baric RS. 2020. SARS-CoV-2 D614G variant exhibits efficient replication ex vivo and transmission in vivo. Science 370:1464-1468.

4. Zhou B, Thao TTN, Hoffmann D, Taddeo A, Ebert N, Labroussaa F, Pohlmann A, King J, Steiner S, Kelly JN, Portmann J, Halwe NJ, Ulrich L, Trueb BS, Fan X, Hoffmann B, Wang L, Thomann L, Lin X, Stalder H, Pozzi B, de Brot S, Jiang N, Cui D, Hossain J, Wilson MM, Keller MW, Stark TJ, Barnes JR, Dijkman R, Jores J, Benarafa C, Wentworth DE, Thiel V, Beer M. 2021. SARS-CoV-2 spike D614G change enhances replication and transmission. Nature 592:122-127.

5. Saito A, Irie T, Suzuki R, Maemura T, Nasser H, Uriu K, Kosugi Y, Shirakawa K, Sadamasu K, Kimura I, Ito J, Wu J, Iwatsuki-Horimoto K, Ito M, Yamayoshi S, Loeber S, Tsuda M, Wang L, Ozono S, Butlertanaka EP, Tanaka YL, Shimizu R, Shimizu K, Yoshimatsu K, Kawabata R, Sakaguchi T, Tokunaga K, Yoshida I, Asakura H, Nagashima M, Kazuma Y, Nomura R, Horisawa Y, Yoshimura K, Takaori-Kondo A, Imai M, Genotype to Phenotype Japan C, Tanaka S, Nakagawa S, Ikeda T, Fukuhara T, Kawaoka Y, Sato K. 2021. Enhanced fusogenicity and pathogenicity of SARSCoV-2 Delta P681R mutation. Nature doi:10.1038/s41586-021-04266-9.

6. Halfmann PJ, lida S, Iwatsuki-Horimoto K, Maemura T, Kiso M, Scheaffer SM, Darling TL, Joshi A, Loeber S, Singh G, Foster SL, Ying B, Case JB, Chong Z, Whitener B, Moliva J, Floyd K, Ujie M, Nakajima N, Ito M, Wright R, Uraki R, Warang P, Gagne M, Li R, Sakai-Tagawa Y, Liu Y, Larson D, Osorio JE, Hernandez-Ortiz JP, Henry AR, Ciouderis K, Florek KR, Patel M, Odle A, Wong LR, Bateman AC, Wang Z, Edara VV, Chong Z, Franks J, Jeevan T, Fabrizio T, DeBeauchamp J, Kercher L, Seiler P, Gonzalez-Reiche AS, Sordillo EM, Chang LA, van Bakel H, et al. 2022. SARS-CoV-2 Omicron virus causes attenuated disease in mice and hamsters. Nature doi:10.1038/s41586-022-04441-6.

7. Zhao H, Lu L, Peng Z, Chen LL, Meng X, Zhang C, Ip JD, Chan WM, Chu AW, Chan $\mathrm{KH}$, Jin DY, Chen H, Yuen KY, To KK. 2022. SARS-CoV-2 Omicron variant shows less efficient replication and fusion activity when compared with Delta variant in TMPRSS2-expressed cells. Emerg Microbes Infect 11:277-283.

8. Hoffmann M, Kleine-Weber H, Schroeder S, Krüger N, Herrler T, Erichsen S, Schiergens TS, Herrler G, Wu NH, Nitsche A, Muller MA, Drosten C, Pohlmann S. 2020. SARS-CoV-2 cell entry depends on ACE2 and TMPRSS2 and is blocked by a clinically proven protease inhibitor. Cell 181:271-280.e8.

9. Hoffmann M, Hofmann-Winkler H, Smith JC, Krüger N, Arora P, Sørensen LK, Søgaard OS, Hasselstrøm JB, Winkler M, Hempel T, Raich L, Olsson S, Danov O, Jonigk D, Yamazoe T, Yamatsuta K, Mizuno H, Ludwig S, Noé F, Kjolby M, Braun A, Sheltzer JM, Pöhlmann S. 2021. Camostat mesylate inhibits SARS-CoV-2 activation by TMPRSS2-related proteases and its metabolite GBPA exerts antiviral activity. EBioMedicine doi:10.1016/j.ebiom.2021.103255:103255. 
bioRxiv preprint doi: https://doi.org/10.1101/2022.01.26.477969; this version posted January $27,2022$. The copyright holder for this preprint (which was not certified by peer review) is the author/funder, who has granted bioRxiv a license to display the preprint in perpetuity. It is made available under aCC-BY-NC-ND 4.0 International license.

10. Kishimoto M, Uemura K, Sanaki T, Sato A, Hall WW, Kariwa H, Orba Y, Sawa H, Sasaki M. 2021. TMPRSS11D and TMPRSS13 activate the SARS-CoV-2 spike protein. Viruses 13:384.

11. Laporte M, Stevaert A, Raeymaekers V, Boogaerts T, Nehlmeier I, Chiu W, Benkheil M, Vanaudenaerde B, Pohlmann S, Naesens L. 2019. Hemagglutinin cleavability, acid stability, and temperature dependence optimize influenza B virus for replication in human airways. J Virol 94:e01430-19.

12. Li F, Han M, Dai P, Xu W, He J, Tao X, Wu Y, Tong X, Xia X, Guo W, Zhou Y, Li Y, Zhu Y, Zhang X, Liu Z, Aji R, Cai X, Li Y, Qu D, Chen Y, Jiang S, Wang Q, Ji H, Xie Y, Sun Y, Lu L, Gao D. 2021. Distinct mechanisms for TMPRSS2 expression explain organ-specific inhibition of SARS-CoV-2 infection by enzalutamide. Nat Commun 12:866.

13. Bestle D, Heindl MR, Limburg $H$, Van Lam van $T$, Pilgram $O$, Moulton $H$, Stein DA, Hardes K, Eickmann M, Dolnik O, Rohde C, Klenk H-D, Garten W, Steinmetzer T, Böttcher-Friebertshäuser E. 2020. TMPRSS2 and furin are both essential for proteolytic activation of SARS-CoV-2 in human airway cells. Life Science Alliance 3:e202000786.

14. Beumer J, Geurts MH, Lamers MM, Puschhof J, Zhang J, van der Vaart J, Mykytyn AZ, Breugem TI, Riesebosch S, Schipper D, van den Doel PB, de Lau W, Pleguezuelos-Manzano C, Busslinger G, Haagmans BL, Clevers H. 2021. A CRISPR/Cas9 genetically engineered organoid biobank reveals essential host factors for coronaviruses. Nat Commun 12:5498.

15. Poh CM, Carissimo G, Wang B, Amrun SN, Lee CY, Chee RS, Fong SW, Yeo NK, Lee WH, Torres-Ruesta A, Leo YS, Chen MI, Tan SY, Chai LYA, Kalimuddin S, Kheng SSG, Thien SY, Young BE, Lye DC, Hanson BJ, Wang CI, Renia L, Ng LFP. 2020. Two linear epitopes on the SARS-CoV-2 spike protein that elicit neutralising antibodies in COVID-19 patients. Nat Commun 11:2806.

16. Vanderheijden N, Stevaert A, Xie J, Ren X, Barbezange C, Noppen S, Desombere I, Verhasselt B, Geldhof P, Vereecke N, Stroobants V, Oh D, Vanhee M, Naesens LMJ, Nauwynck HJ. 2022. Functional analysis of human and feline coronavirus crossreactive antibodies directed against the SARS-CoV-2 fusion peptide. Front Immunol 12.

17. Voss C, Esmail S, Liu X, Knauer MJ, Ackloo S, Kaneko T, Lowes L, Stogios P, Seitova A, Hutchinson A, Yusifov F, Skarina T, Evdokimova E, Loppnau P, Ghiabi P, Haijan T, Zhong S, Abdoh H, Hedley BD, Bhayana V, Martin CM, Slessarev M, ChinYee B, Fraser DD, Chin-Yee I, Li SS. 2021. Epitope-specific antibody responses differentiate COVID-19 outcomes and variants of concern. JCI Insight 6:e148855.

18. Schaefer SL, Jung H, Hummer G. 2021. Binding of SARS-CoV-2 fusion peptide to host endosome and plasma membrane. J Phys Chem B 125:7732-7741.

19. Coutard B, Valle C, de Lamballerie X, Canard B, Seidah NG, Decroly E. 2020. The spike glycoprotein of the new coronavirus 2019-nCoV contains a furin-like cleavage site absent in CoV of the same clade. Antiviral Res 176:104742.

20. Tang T, Bidon M, Jaimes JA, Whittaker GR, Daniel S. 2020. Coronavirus membrane fusion mechanism offers a potential target for antiviral development. Antiviral Res 178:104792.

21. Bertram S, Dijkman R, Habjan M, Heurich A, Gierer S, Glowacka I, Welsch K, Winkler M, Schneider H, Hofmann-Winkler H, Thiel V, Pöhlmann S. 2013. TMPRSS2 activates the human coronavirus $229 \mathrm{E}$ for cathepsin-independent host cell entry and is expressed in viral target cells in the respiratory epithelium. J Virol 87:6150-60.

22. Lucas JM, Heinlein C, Kim T, Hernandez SA, Malik MS, True LD, Morrissey C, Corey E, Montgomery B, Mostaghel E, Clegg N, Coleman I, Brown CM, Schneider EL, Craik C, Simon JA, Bedalov A, Nelson PS. 2014. The androgen-regulated protease TMPRSS2 activates a proteolytic cascade involving components of the tumor microenvironment and promotes prostate cancer metastasis. Cancer Discov 4:131025. 
23. Okumura Y, Takahashi E, Yano M, Ohuchi M, Daidoji T, Nakaya T, Böttcher E, Garten W, Klenk HD, Kido H. 2010. Novel type II transmembrane serine proteases, MSPL and TMPRSS13, proteolytically activate membrane fusion activity of the hemagglutinin of highly pathogenic avian influenza viruses and induce their multicycle replication. J Virol 84:5089-96.

24. Kim DR, Sharmin S, Inoue M, Kido H. 2001. Cloning and expression of novel mosaic serine proteases with and without a transmembrane domain from human lung. Biochim Biophys Acta 1518:204-9.

25. Elbe S, Buckland-Merrett G. 2017. Data, disease and diplomacy: GISAID's innovative contribution to global health. Glob Chall 1:33-46. 

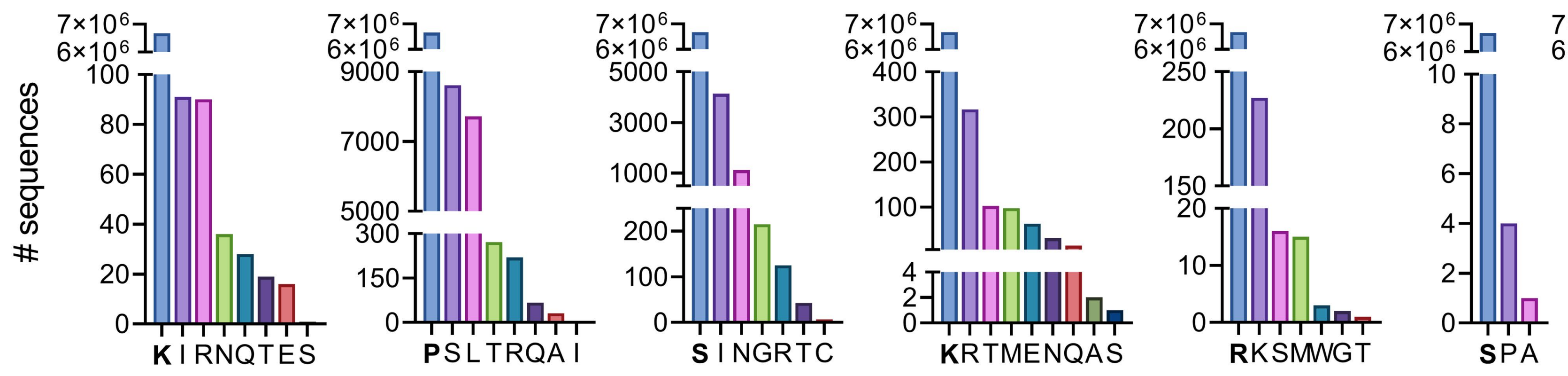

$7 \times 10^{6}$
$6 \times 10^{6}$

B
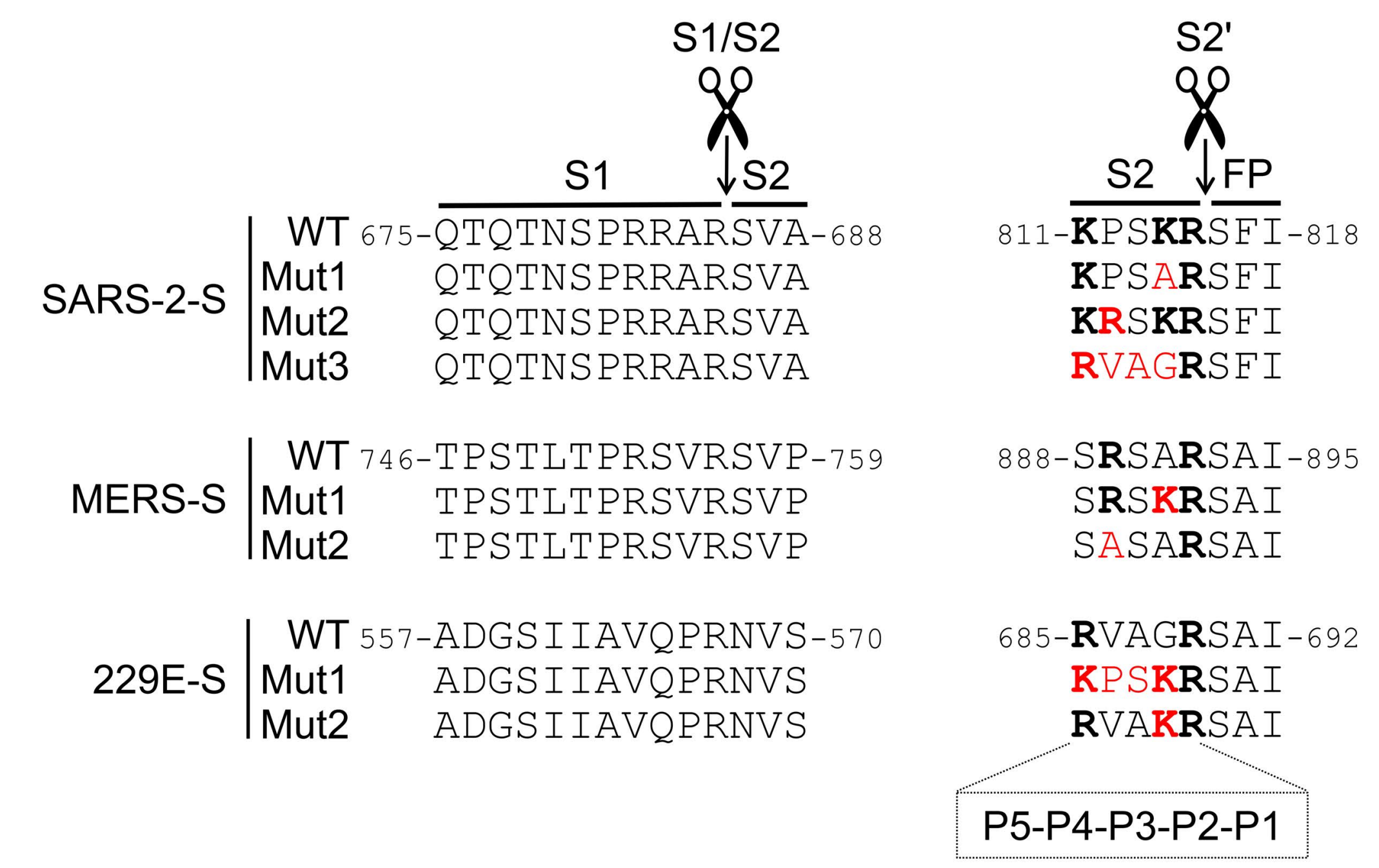

FIGURE 1. S2' site variation in circulating SARSCoV-2 isolates and mutations introduced in this study. A. Variation analysis of the S2' site was performed on $6,679,700$ SARS-2-S sequences downloaded from the GISAID database. B. Partial alignment of wild-type (WT) SARS-2-S, MERS-S and $229 \mathrm{E}-\mathrm{S}$, and the S2' mutants created in this study. In red: amino acid changes versus WT; in bold: basic (i.e. $\mathrm{R}$ or $\mathrm{K}$ ) residues. 
